\title{
Impact of Lymphatic Filariasis on Married Women from Rural Areas of Bankura District, West Bengal, India
}

\author{
Manas Paramanik', Niladri Sarkar', Goutam Chandra ${ }^{3}$
}

${ }^{1}$ Assistant Professor, Department of Animal Science, Kazi Nazrul University, Asansol, Paschim Bardhaman, West Bengal, India. ${ }^{2}$ Professor, Department of Medicine, The Institute of Post-Graduate Medical Education and Research and Seth Sukhlal Karnani Memorial Hospital, Harish Mukherjee Road, Bhwanipur, Kolkata, West Bengal, India.

${ }^{3}$ Professor, Parasitology Laboratory, Mosquito and Microbiology Research Units, Department of Zoology, The University of Burdwan, Golapbag, Burdwan East, West Bengal, India.

DOI: https://doi.org/10.24321/0019.5138.202105

I $\quad \begin{array}{lllll}\mathbf{N} & \mathbf{F} & \mathbf{O}\end{array}$

Corresponding Author:

Goutam Chandra, Parasitology Laboratory, Mosquito and Microbiology Research Units, Department of Zoology, The University of Burdwan, Golapbag, Burdwan East, West Bengal, India.

E-mail Id:

goutamchandra63@yahoo.co.in

Orcid Id:

https://orcid.org/0000-0002-6485-8562

How to cite this article:

Paramanik M, Sarkar N, Chandra G. Impact of Lymphatic Filariasis on Married Women from Rural Areas of Bankura District, West Bengal, India. J Commun Dis 2021; 53(1): 23-26.

Date of Submission: 2021-02-11

Date of Acceptance: 2021-02-25
$\begin{array}{llllllll}\mathbf{A} & \mathbf{B} & \mathbf{S} & \mathbf{T} & \mathbf{R} & \mathbf{A} & \mathbf{C} & \mathbf{T}\end{array}$

In third world countries like India, women play a vital role in building and maintaining the family and the society. Lymphatic Filariasis (LF) among married women may inflict a deep impact on the society. Present study was focused to study the impact of LF on married women of some rural areas of Bankura district in West Bengal, India. Night blood-samples of 1202 married women were examined to detect the presence of microfilariae. They were examined clinically and also asked for any hidden filarial manifestation. Affected subjects were also interrogated to understand the impact of LF on their lives. Microfilaria rate, mean microfilaria density and disease rate among the married women of the area were assessed as $6.16 \%, 10.89 \%$ and $11.98 \%$ respectively. $95.83 \%$ of the diseased subjects were of opinion that the disease had imposed some or many adverse effects on their lives. The diseased women suffer from disability, loss of efficiency and social stigma. They are often neglected and abstain themselves from intimating their problems to the family members and seeking help for various reasons. Awareness level is poor and presumably the situation is same in the rural areas of other under developed and developing countries.

Keywords: Lymphatic Filariasis, Married Women, Rural Areas, Impact

\section{Introduction}

Lymphatic Filariasis (LF) is one of the most devastating and disabling diseases of the world, capable of imposing a substantial impact on the suffering population. ${ }^{1-3}$ Worldwide over 120 million people are infected with LF, about 40 million among them suffer from clinical manifestations and almost 15 million, the majority of whom are women, have lymphoedema or filariasis. ${ }^{1}$ The disease affects both males and females but its impact on females is often neglected drawing very little public interest.

Epidemiological evidences on LF of different age groups of male and female subjects are available from different areas of West Bengal in India, ${ }^{4-10}$ but specific research on impact of LF on rural married women is scanty. ${ }^{11} \mathrm{~A}$ small initiative 
was taken in the present study to obtain information about the filarial epidemiology and its effect among the married women of some rural villages under Banashuria grampanchayet in Bankura district, West Bengal, India.

\section{Materials and Methods}

1202 married women from rural villages of Banashuria gram-panchayet of Bankura district were included in the study, selected by mode of random sampling following pioneer workers. ${ }^{12,13}$ Before execution of the work, written informed consent for participation in the study was obtained from participants.

Necessary ethical approval for the study has been taken from the "Institutional Clinical Ethical Committee of The University of Burdwan" [IEC(BU)/2016/5, dated 24/08/2016]. All ethical standards were maintained during the study.

$20 \mu \mathrm{L}$ night blood samples were collected from all the subjects by finger prick and examined for the presence of microfilariae, if any. ${ }^{14}$ Each subject was examined clinically by a medical personal for the signs of filarial aetiologies and asked about their symptoms following World Health Organization (WHO) guidelines. ${ }^{15}$ After the primary survey, all the detected LF affected women were studied separately to know the impact of the disease on them. This study was mainly based on several interviews using semi-structured questionnaires. The study was conducted during September 2016 to August 2018.

Available data were subjected to statistical analyses using student's' $t$ ' test and standard normal deviate ' $Z$ '. ${ }^{13}$

\section{Result}

Among the 1202 studied women 74 were detected to be Wuchereria bancrofti microfilaremics [microfilaria rate (MR) 6.16\%] and 144 with filarial aetiologies [disease rate (DR) 11.98\%], with overall Endemicity Rate (ER) of $17.80 \%$. Mean Microfilarial Density (MMD) among the microfilaremics were calculated as 10.89. Different filarial aetiologies encountered among the married women during the study were Adeno-lymphangitis (4.49\%), Lymphoedema (3.99\%), and Elephantiasis of leg (3.49\%). An age group wise (younger, middle and older age) epidemiological data are presented in 'Table1' and an age group wise distribution of different aetiologies were presented in 'Figure 1'. Four diseased women were detected as microfilaremic also.

About $95.83 \%$ of the diseased women were of opinion that the disease imposed some or many awful impacts on them, whereas none of the microfilaremics complained for any major problem (some complained about fever but it was not indicated that those were due to $W$. bancrofti infection) and obviously not conscious that they were carrier of $W$. bancrofti.

About 24 (16.67\%) of the diseased women suspected that they were infected with filarial parasites before marriage and others claimed to acquire the infection after marriage. Among the former group, 22 (91.67\%) women admitted that they did not disclose this fact to their future marriage partners during pre-marriage negotiation visits. In private discussion, 8 middle aged women swear that they did not unveil their pre-marriage infection even after spending more than 10 years of marriage life, rather their families/ husbands considered that infection, was acquired 'after' marriage.

$41.67 \%$ of the diseased persons were of opinion that, their family members took their problems sportingly but rest thought that their position in the family or society was subordinate due to disease manifestations.

Among the LF diseased married women under study, about $70.83 \%$ was found to be deprived from sufficient medical attention for different reasons and $76.89 \%$ felt embarrassed to disclose their filarial disease manifestations to others. $59.72 \%$ possessed the basic knowledge that their disease may be acquired from mosquito bites, but only $48.61 \%$ were adequately aware of 'regular' campaigning, awareness or Mass Drug Administration (MDA) programmes in the area.

Table I.Epidemiological data of lymphatic filariasis among the married women of rural villages of Banashuria gram-panchayet of Bankura district of West Bengal, India

\begin{tabular}{|c|c|c|c|c|}
\hline Parameters & $\begin{array}{c}\text { Younger age } \\
\text { group } \\
(\leq \mathbf{3 0} \text { years })\end{array}$ & $\begin{array}{c}\text { Middle age group } \\
(\mathbf{3 1 - 5 0} \text { years })\end{array}$ & $\begin{array}{c}\text { Older age group } \\
(\mathbf{2 5 1} \text { years })\end{array}$ & Overall \\
\hline Number of studied women & 482 & 402 & 318 & 1202 \\
\hline Microfilaria rate & 2.49 & 10.45 & 6.29 & 6.16 \\
\hline Mean microfilarial density & 5.67 & 12.90 & 9.80 & 10.89 \\
\hline Disease rate & 9.54 & 12.94 & 14.47 & 11.98 \\
\hline Endemicity rate & 12.03 & 22.89 & 20.13 & 17.80 \\
\hline
\end{tabular}




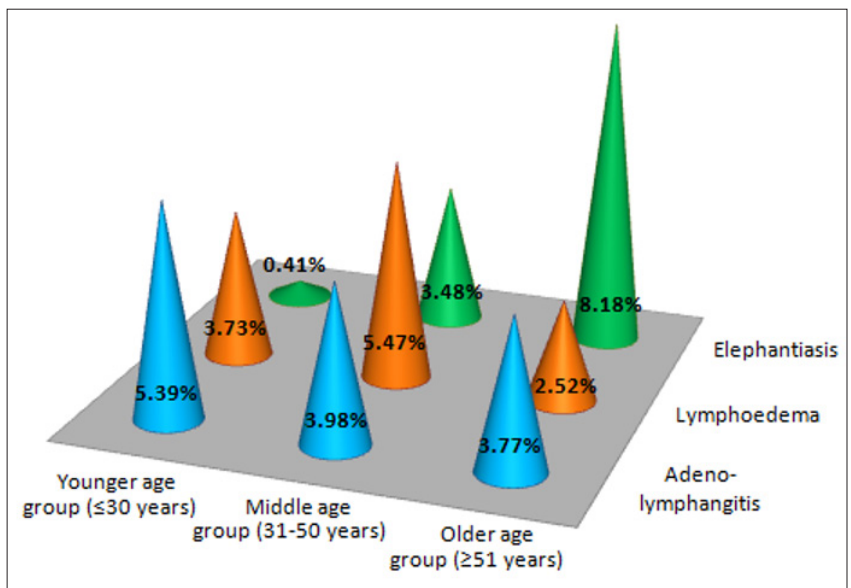

Figure I. Age group wise distribution of different aetiologies among the married women of rural villages of Banashuria gram-panchayet of Bankura district of West Bengal, India

\section{Discussion}

The study area is endemic for LF. ${ }^{16}$ Most of the married women of the area are deprived of higher education often with very little awareness about health and hygiene. Mainly they are housewives but a large proportion (mostly the backward poorer section) also work as low income daily labourers in unorganised sectors (like farming, construction, housekeeping etc.) to support their family financially.

Epidemiological data reveals that $\mathrm{MR}, \mathrm{MMD}$ and ER among the married women are higher in the middle age group [difference with the younger group is significant $(P<0.05)$ but with the older group is insignificant $(P>0.05)]$, whereas DR was higher in the older age group [difference is not significant with both younger and middle groups ( $P>0.05)$ ]. So it appears that the younger age married women are less affected by LF, because (i) they use more cloths and less exposed to mosquito bites and (ii) some of them come to the area after marriage from less endemic areas (in Indian society after marriage most women come to stay in husband's house). But with increasing age they tend to become affected by LF and develop different clinical manifestations (or disease) like Elephantiasis etc., which are evident from the study results (Table 1 and Figure 1). Unlike of men, women are more often infected in or around their houses, ${ }^{17}$ facilitated by the presence of vector breeding sites near the house and other factors related to the vector and filarial transmission. ${ }^{18-20}$

Majority of the married women under study, who are affected by LF aetiologies, are facing problems $(P<0.05)$.

Pre-married infected women often face difficulty to find a spouse of their choice which induces them to hide their disease. Those who disclose their pre-married manifestations before marriage face problems in finding suitable marriage partner. In many endemic areas, including the present one, a LF affected women is often considered to have reduced ability of working, taking care of family members and children, which leads their marriage prospect diminished. ${ }^{21,22}$ Some time there is a misperception that children may inherit the parasite/disease from their mothers with notable expression of the LF diseases. So, diseased mothers find it difficult to search a suitable match for their daughters as also reported by other researchers. ${ }^{23,24}$

Filarial aetiologies are frequent in the study area. Sometime the village people are sympathetic to the problems of the diseased persons; but in majority of cases they are humiliated through awkward comments. Even, without any proof, some of the husbands suspect that their spouse is carrying pre-married infection.

The study suggests that sufficient medical attention to the LF affected married women are scanty in the area. Many of them are unaware that their manifestations can be reduced by treatment. It was also appears that, at times the family members did not show sufficient interest in treatment or to escort their females to a medical authority due to neglected status of the women or assumed expenditures. But in other cases the patient themselves may not seek treatment due to social or cultural restrictions, feeling of shame etc. Working women were always anxious about loss of working ability and earnings. These may refrain them from reporting or assessing problems and seeking helps. ${ }^{11}$

In countries like India, married women take a great role in building up of the family and propagating the basic knowledge to their children and the community. But social status of married women is often neglected and their role in building the family and society is not often given due recognition. Disease like LF may make their position worse. The present study depicts that, basic knowledge about LF and its vectors is scanty among them, itself. Community perception and participation about LF of married women is also not up to the mark. For these reasons, disability, loss of productivity, mental ambiguity and social stigmatization due to LF are very common. Similar situation may also occur in the rural areas of other under developed and developing countries, and should be considered during policy-making.

According to Bandyopadhyay women are silently bearing the brunt of LF. ${ }^{11}$ In the endemic areas, proper implementation of LF management programme (including awareness programmes, proper coverage of MDA and free treatment) among them can reduce LF infection and morbidity to a great extent, which may be beneficial for entire society and helpful in achieving the goal of Global Programme to Eliminate LF.

Funding: None

Conflict of Interest: None 


\section{References}

1. WHO. Progress report 2000-2009 and strategic plan 2010-2020 of the global programme to eliminate lymphatic filariasis: halfway towards eliminating lymphatic filariasis. 2010. Available from: https://apps. who.int/iris/handle/10665/44473.

2. WHO. Global programme to eliminate lymphatic filariasis: progress report on mass drug administration 2010. Weekly Epidemiol Rec 2011; 86: 377-388.

3. Chandy A, Thakur AS, Singh MP et al. A review of neglected tropical diseases: filariasis. Asian Pac J Trop Med 2011: 4(7): 581-586.

4. Hati AK, Chandra G, Bhattacharya A et al. Annual Transmission Potential of bancroftian filariasis in an urban and a rural area of West Bengal, India. American J Trop Med Hyg 1989; 40: 365-367.

5. Adhikari P, Haldar S, Ghosh NR et al. Prevalence of Bancroftian filariasis in Burdwan district, W.B. A comparative study between colliery and non-colliery areas. J Commun Dis 1994; 26: 6-13.

6. Singh $S$, Bora D, Sharma RC et al. Bancroftian filariasis in Bagdogra town, district Darjeeling (West Bengal). J Commun Dis 2002; 34: 110-117.

7. Das SK, Ghosh A, Behera MK et al. Studies on Vector of Bancroftian filariasis at Katwa, West Bengal. J Parasit Appl Anim Biol 2003; 12: 1-7.

8. Chandra G, Chatterjee SN, Das S et al. Lymphatic filariasis in the coastal areas of Digha, West Bengal, India. Tropical Doctor 2007; 37: 136-139.

9. Paramanik M, Chandra G. Lymphatic filariasis in the foothill areas around Susunia of West Bengal in India. Asian Pac J Trop Med 2009; 2: 20-25.

10. Chandra G, Mondal SK, Paramanik M et al. Comparative Epidemiological Studies on Lymphatic Filariasis among the Population of a Rural and an Urban Area of West Bengal, India. Trop Med Surg 2013; 1: 103.

11. Bandyopadhyay L. Lymphatic filariasis and the women of India. Soc Sci Med 1996; 42: 1401-0.

12. Yates DS, Moore DS, Starnes DS. The Practice of Statistics. $3^{\text {rd }}$ ed. Freeman, 2008.

13. Zar JH. Biostatistical analysis. $5^{\text {th }}$ ed. Pearson Prentice Hall, New Jersey. 2010.

14. Gubler DJ, Inui TS, Black HR et al. Comparison of microfilaria density in blood sample by fingerprick, venipuncture and ingestion by mosquito. Am J Trop Med Hyg 1973; 22: 174-178.

15. WHO. Lymphatic filariasis. The disease and its control, Fifth report of the WHO Expert Committee on Filariasis. WHO Technical Report Series 1992; 821: 1-71.

16. Chandra G, Paramanik M. Effect of single to triple dose DEC on microfilaremics up to 5 years. Parasitology Research 2008; 103: 1279-1282.

17. Chesnais CB, Missamou F, Pion SD et al. A case study of risk factors for lymphatic filariasis in the Republic of Congo. Parasites \& Vectors 2014; 7: 300.

18. Paramanik M, Chandra G. Studies on breeding habitats and density of postembryonic immature filarial vector in a filarial endemic area. Asian Pac J Trop Biomed 2012; 2: 1869-1873.

19. Paramanik M, Chandra G. Studies on seasonal fluctuation of different indices related to filarial vector, Culex quinquefasciatus around foothills of Susunia of West Bengal, India. Asian Pac J Trop Med 2010; 3: 727-730.

20. Chandra G. Peak period of filarial transmission. Am J Trop Med Hyg 1995; 53(4): 378-379.

21. Gyapong $M$, Gyapong JO, Adjei $S$ et al. Filariasis in Northern Ghana: some cultural beliefs and practices and their implication for disease control. Soc Sci Med 1996; 43: 235-242.

22. Coreil J, Mayard G, Louis-Charles J et al. Filarial elephantiasis among Haitian women: social context and behavioural factors in treatment. Trop Med Int Health 1998; 3: 467-473.

23. Krishnakumari A, Harichandrakumar KT, Das LK et al. Physical and psychosocial burden due to lymphatic filariasis as perceived by patients and medical experts. Trop Med Int Health 2005; 10: 567-573.

24. Wynd S, Melrose WD, Durrheim DN et al. Understanding the community impact of lymphatic filariasis: a review of the sociocultural literature. Bulletin of the World Health Organization 2007; 85: 493-498. 